\title{
PART THIRD.
}

\section{Brígínal Communícations.}

\section{ART. I. \\ On the Influence of Sex in Hereditary Disease. By William Sedgwick.}

Thene are few subjects in medicine more important than the family history of disease, and there are perhaps few, if any, in which more error and uncertainty prevail. It is chiefly in consequence of this, that whilst all medical observers are more or less ready to obtain information from this source, yet the result of their inquiry is for the most part too unsatisfactory to be of much practical value, for in addition to the apparently contradictory nature of some of the positive evidence obtained, there is often a well-grounded suspicion attached to a large proportion of the negative evidence on the subject, resulting from the unwillingness of relatives to admit the truth in those cases in which it is supposed that its suppression can do the patient no harm, as well as occasionally from a desire on their part to mislead in those cases in which their own feelings or interests are involved, when the question of hereditariness in disease seems to approach too near not to be denied. To these obstacles in the way of obtaining trustworthy evidence must be added the errors resulting from omission on the part of the inquirer, both as regards the extent to which the investigation of hereditary disease is carried, so that the medical history of collateral and remote members of the family is often neglected, and also as regards the prevailing tendency to limit the inquiry to such cases chiefly as present some novel or important peculiarity, in consequence of which many of the recorded cases of hereditary disease are commonly looked upon as morbid curiosities, and are cited only to illustrate what are called "the freaks of nature." Notwithstanding, therefore, the great progress which has been made of late years in other departments of medicine, very little useful information has been added to our previous knowledge respecting the hereditariness of disease, for, beyond some occasional and isolated cases, there are few records of any extent respecting the family history of a single class of what may be called common diseases, except, it may be, the mental, all inquiry into which is beset with such great difficulty that the information obtained is often without value; and in reference to disease generally, if cases of colour blindness and the hæmorrhagic diathesis be

62-xxxi. 
excluded, there are not, so far as I have been able to ascertain, any well recorded series of cases of any disease or defect in which the family history has been fully investigated even for only three generations, short of which no negative evidence connected with the hereditariness of disease is of much value.

The object of the present inquiry is to determine how far hereditary disease is subject to any rule or controlling influence capable of regulating its course and restricting its development. so as to produce some degree of order both in its appearance and transmission, as opposed to the commonly accepted view that both its course and its development are ton uncertain and irregular for any controlling power to restrict either the one or the other within certain and well-defined limits; as was once thought to be the case in ordinary travelling before rails were invented, which now, by regulating and restricting the course of the carriage, ensure rapid and continued progress in the right way. In an introductory paper on this subject,* I called attention to the importance of sexual limitation, and briefly referred to the general nature and extent of its influence both on the development and transmission of hereditary disease; and it is proposed in the following pages to continue the same inquiry, not on account of sexual limitation being the only, or in some cases the chief, influence capable of controlling hereditary disease, for there are not unfrequently other influences more or less important, either associated with or independent of it, but on account of there being much in my former paper on the subject which needs to be more fully illustrated and confirmed, before the influence of sex on disease will be satisfactorily established, or the result of the inquiry can be favourably received. From the limited opportunities which have been offered for investigating this subject, it would be somewhat premature for me at present to draw any general conclusions; but from what has been already ascertained, it is not unreasonable to infer that if due attention were shown in "taking" the history of all diseases, so as to determine how far not only the immediate parents or relations of the patient were similarly or not affected, but also the condition of the grand-parents on both sides, and all collateral relations in the order of their birth, that we should possess a series of records of great practical value for determining the extent to which disease is liable to recur in successive generations, and also the probability of its affecting individual members of the same family. If such an investigation could for only one year be consistently carried out at one of our large metropolitan hospitals, where the great number and variety of the cases daily brought under notice, and the almost unlimited means at the command of the medical staff for following up such researches, afford opportunities which far exceed those which are met with in private practice, it is probable that our literature, like that of other countries, would in time be enriched with some useful works, instead of being now, as regards special treatises on the subject, almost exclusively confined to one author (Mr. Joseph

* British and Foreign Medico-Chirurgical Review, April and July, 1861. 
Adams) and one work, written chiefly to disprove the inheritance of disease.

In any inquiry respecting the influence of sex in hereditary disease, the cases to be referred to must necessarily be very varied and very numerous, and it has therefore appeared to be a good plan to select for consideration those chiefly which admit of being grouped together in some natural order, so as to avoid the confusion which would result from citing a large number of cases having no common bond of union derivable either from the nature or the seat of the disease itself. With this object in view, it was thought desirable, in the introductory paper on this subject, to refer chiefly to those diseases and peculiarities which affect hereditarily the skin and its dependencies, in which the principle of sexual limitation appears to be particularly well marked. It is proposed to follow out to some extent the same plan now, by citing in the first instance some corroborative cases belonging to the large group already referred to, and then proceeding to illustrate the subject by such additional cases as admit of being referred to some anatomical division of the body, such as the upper and the lower extremities; to some physiological division, such as the cerebral, circulatory, and respiratory systems; and lastly, to notice briefly such other cases as may not have been included under the preceding heads.

Subsequent research has tended to confirm the opinion which was advanced in the paper already referred to, that sexual limitation, although met with in all forms of hereditary disease, is more constant and more strongly defined in those diseases affecting hereditarily the skin and its dependencies, than in those affecting the other organs or tissues of the body; and in thus drawing attention to sexual limitation as more frequent in the hereditary affections of these structures than in those of internal parts, it must not be supposed that there is anything unexpected in its occurrence under these circumstances, for it might be inferred from analogy that if such restriction hy sex was a characteristic phenomenon in disease, it would be especially so in connexion with the skin and its appendages, which naturally present peculiarities dependent on sex, which we fail generally to recognise in the structure of internal organs; and in many of the lower animals, as, for example, in the plumage of birds, and in the external structures of insects and other invertebrate animals, the contrast is so great that naturalists have often, by mistake, referred the external and hereditary distinctions of sex to difference of species. In addition, therefore, to the cases already adduced in support of this opinion, the following have been cited to show that on this point the evidence can be almost indefinitely increased, and that further inquiry may be expected to lead to the same or similar results.

With respect to diseases of the skin proper, Rayer* states that the hereditary nature "of many cutaneous affections is one of the bestestablished facts in pathology," and that "it often follows the law of resemblance and sometimes that of sex;" and he has published some

* A Theoretical and Practical Treatise on the Diseases of the Skin, by P. Rayer, M.D., second edition, 1835, p. 29 . Translated by R. Willis, M.D. 
interesting cases which may be quoted to illustrate this point. One is a case of general ichthyosis in two brothers; neither the father, mother, nor three sisters had the disease.* In another case, three brothers in one family suffered from ichthyosis.t Similar observations have been made respecting allied forms of skin disease, such as leprosy, psoriasis, and lepra, which are so often hereditary that Alibert, $\neq$ in allusion to the latter, remarks, "nearly all the world agrees in saying that hereditariness is the most frequent cause of lepra." The great frequency of leprosy (sometimes called radesyge) in the northern states of Europe has been already referred to, as well as the severe measures which have been proposed to abate the evil. The disease seems to prevail chiefly in countries imperfectly civilized, and was formerly very common in England and Scotland, as is well shown to have been the case by Dr. James Y. Simpson, in his 'Antiquarian Notices of Leprosy and Leper Hospitals in Scotland and England,' which contains the following rase of the direct transmission of leprosy from father to son: "In the Burgh records of Glasgow for 1581, Patrick Bogle is ordered to be inspected for leprosy; and eight years afterwards (1589), 'Robert Bogill, sone to Patrick Bogle,' is reported to as an inmate of the leperhouse belonging to the city." $\$$ This case is interesting, not merely as an early record of hereditary leprosy, but as an illustration of its direct inheritance in the male line, for it has lately been asserted, and apparently with some reason, to be more commonly transmitted by collateral and atavic, rather than direct descent. In whatever way the trausmission may be effected, there is a very general belief in the hereditary character of the disease, and this popular opinion seems to rest, not on any fanciful assumption, but on the fact that different members of the same family have been subject to it; and in addition to what has been already stated respecting the hereditary nature of the disease in comparatively modern times, it may be further urged that Tamerlane, in his widely-extended conquests, everywhere ordered lepers to be exterminated: that in Scotland, where leprosy appears to have been formerly very common, male lepers were, it is said, by law, ordered to be castrated, a practice which it has lately been proposed to revive in Norway and Sweden; and that the attempt made in 1854 by the Royal Commission on Leprosy in Norway to establish a law prohibiting the marriage of lepers would probably have been successful but for the strenuous opposition of Dr. Hjort, who maintains that the disease is not hereditary. This opinion of Dr. Hjort has been very warmly contested by Drs. Boeck and Danielssen, \| who have adduced evidence to show that whilst leprosy is a thoroughly hereditary disease, it descends more by collateral branches than by immediate succession, and that it also frequently skips over one, two, or three generations, to reappear with fearful severity in the fourth. This statement is quite consistent with what has been observed respecting the inheritance of

* Rayer, loc. cit., p. 972.

† Ibid., p. 973.

¥ Déscription des Maladies de la Peau, p. 144. Par J. L. Alibert. Paris, 1814. $\$$ Edinburgh Medical and Surgical Journal, vol. lvii. p. 405. 1842.

II British and Foreign Medico-Chirurgical Review, April, 1858, pp. 336-7. 
other diseases, and it not only removes many difficulties, but also reconciles many apparent contradictions, as it will be my endeavour to show in some general and concluding remarks which it is proposed to offer on the nature of atavism as associated with limitation by sex in hereditary disease: and some additional information on this subject may shortly be expected as the result of our own Government Commission of Inquiry on Leprosy in the West Indies.

In the following case of hereditary pityriasis versicolor, for which I am indebted to Dr. H. Stewart, there was limitation by age as well as sex, and moreover atavism through the opposite sex occurred when females intervened to check its direct transmission to males :-A single man, aged twenty-four years, and the eldest son of a family consisting of two sons and two daughters, has well-marked pityriasis versicolor affecting his chest, neck, back, and arms, and which was first observed when he was about fourteen years of age; his brother, now twenty years of age, has it, though not to the same extent; and his father, paternal uncies, paternal grandfather, and seven male cousins on the paternal side, have all been similarly affected; the disease, strictly limited to the males, usually appeared in all of them at puberty, and disappeared.about the age of forty or forty-five years; whilst the females of the family, although not suffering from it themselves, have transmitted it to their male children. Dr. Caillault has recorded a case "of local pityriasis in a family consisting of ten children, three girls and seven boys; all the boys, when abuut four or five years of age, were attacked by persistent pityriasis palmaris."* In a stronglymarked case of "Discoloration of the Skin of the Fore-arms and Hands during Pregnancy," brought before the notice of the Obstetrical Society, February 5th, 1682, and which had affected the patient in each of her four pregnancies, commencing at the fourth month, and increasing in intensity from that time, the mother had been similarly affected. A similar case to the preceding has presented itself in my own practice, which possesses additional interest from the fact that whilst bronzing of the skin has hereditarily affected the females, a peculiar and congenital distortion of the little fingers has hereditarily characterized the males: a married woman, aged thirty-four years, the eldest of a family consisting of two daughters and one son, has wellmarked bronzing of the skin, especially well marked over the face and forehead, arms and wrists, trunk of the body in front, and upper part of the thighs, which commenced at the age of twenty-five years, during her first pregnancy, and diminished, but did not disappear after delivery; in each succeeding pregnancy the bronzing was progressively more marked, and its diminution after delivery became correspondingly less, so that there is now a very noticeable and permanently bronzed condition of the skin over a great part of the body; her sister, aged thirty-one years, who has also several children, presents the same bronzed condition of the skin, which commenced during her first pregnancy, and has gone through the same progressive

* A Practical Treatise on Diseases of the Skin in Children : from the French of Caillault, p. 139. With Notes by R. H. Blake. 1861. 
changes; her brother, aged twenty-nine years, who is married and has a family, is quite unaffected by it; but their mother, who died at the age of fifty-two years, from what is stated to have been disease of the kidneys, had strongly-marked bronzing of the skin, which commenced during her first pregnancy, and followed the same developmental changes: it could not be ascertained whether any other members of the family had been similarly affected.

In addition to the cases of congenital leucopathia previously referred to as hereditarily limited to one sex, I may cite the case observed by M. Rayer,* of Lonisa de Brun, aged three years, native of Paris, and an albiness; her sister, aged fifteen years, was also an albiness, and their mother had hair of the very lightest kind: M. Arthaud'st case of female twin albinoes, in the Antilles: and a case referred to by Cox, of three albino women in one family. And observation has led M. Girou, $\S$ he informs us, to make the following general remark, that " the son resembles sometimes the father by the colour of the skin, and the mother in form; whilst the daughter resembles the father in form, and the mother by the colour of the skin."

In the family of one of my patients at present under observation, warts on the hands have been hereditarily limited to the female line for two generations; the mother herself was much troubled with numerous warts on both hands, which appeared in infancy, continued during childhood, and disappeared soon after puberty; she has had five children-viz., James, aged eleven years; Ellen, aged nine years; Clara, aged seven years; George, aged five years (since dead); and Rosa, aged two years and a half ; the two sons have never had a wart, whilst all of the three daughters are troubled with them. The eldest danghter has at present thirty, and the next daughter has twenty-four warts on the two hands, which commenced in each case during infancy, and have gradually increased in number since; the youngest daughter has at present two small warts. It cannot be ascertained whether any sinilar tendency to this warty disfigurement of the hands has occurred in other branches of the family. And the same limitation has been observed in the unhorned varieties of oxen, sheep, and goats, which are descended from animals in which the peculiarity appears to have been at first restricted in some degree by sex; for Azarall states, that the now common race of oxen in Paraguay is derived from a bull which was accidentally without horns, and implanted this vice upon all its male progeny.

In the following two cases of sebaceous tumours of the scalp, which occurred in the practice of Dr. Henry Stewart, and which were hereditarily limited to the female sex, in the first case for ten, and in the second case for five generations, it will, moreover, be observed, that in the first case limitation by age as well as by sex occurred, and also

* Op. cit. p. 935 .

† Observations sur les Albinoes, in Journal de Phys., 1789, part 2, p. 276.

$\ddagger$ Cox : Philadelphia Medical Museum, vol. i. p. 151.

$\S$ De la Génération, pp. 131-2. 1828.

|| Reise nach Südamerika, p. 161. Berlin, 1810. 
that some of the females derived the inheritance from their paternal grandmother by atavic descent, which affords an additional proof of the influence of sex, for except when a male thus intervened to arrest the appearance of the disease, the inheritance was direct from parent to child.

First Case.-The wife of a painter, aged fifty-four years, has thirtythree sebaceous tumours on the scalp, none of which are larger than a walnut; but thirteen years ago, nine sebaceous tumours, varying in size from a nutmeg to a small orange, were excised by the late Mr. Morton, with considerable relief to the severe headaches she had previously suffered from; her daughter and her grand-daughter are both affected by them, her sons are perfectly free; her brother's daughters are troubled with them, as well as several female cousins of different degrees of relationship; her mother, grandmother, and female relations backwards for seven generations, were similarly affected; no female who had attained her tenth year of age was without them, whilst none of the males in the family had ever had them.

Second Case.-A single woman, aged thirty years, the only child of her parents, and suffering from phthisis in the second stage, which she has inherited from her mother's family, has ten sebaceous tumours on the scalp, varying in size from a nutmeg to a pea, and which were first observed when she was about fifteen years of age; these tumours have been common to the females of her mother's family-her mother, maternal grandmother, maternal great-grandmother, and maternal great-great-grandmother all had them, and so likewise have several female cousins on the mother's side of the first and second degrees of relationship; all the females, but none of the males, in the family have suffered from them.

From hereditary affections of the skin proper we may pass to those of the hair, in which the same tendency to limitation by sex will be often found to prevail. As regards the colour of the hair, Siebold* records the case of a married couple whose fathers were both redheaded, but not having red hair themselves, who had four sons redheaded, and three daughters whose hair was of another colour. This case accords with the following observations by Girou, + on the same subject: "I have seen reappear in male foals the hair of their grandfather, and in young mares that of their grandmother, although it has nut been found either in the father or in the mother "' and so likewise with respect to other animals, Girou remarks that, "one is often surprised to see lambs black, or spotted with black, born of ewes and rams with white wool; but if one takes the trouble to go back to the origin of the phenomenon, it is found in the ancestors." In the following case, the associated influence of atavism was partly but not exclusively concerned in the limitation by sex of the colour of the hair ; a sporting-dog, the issue of a setter mother and a spaniel father, was coupled with a setter bitch, and the male offspring were spaniels like the paternal grandfather, and resembled him in their hair, 
whilst the female offspring were setters, having the colour of their mother.*

In addition to such cases there are many others of an imperfect character, in which no particulars of the family history have been given, such as the case referred to by Portal, $\dagger$ of a well-known French family, remarkable for their enormous black eyebrows; and the case lately cited by Dr. Hodgkin, $\$$ of a noble family in this country, in which "every member had a lock of hair of a lighter colour than the rest on the top of the head." As the information afforded in these cases is very indefinite, and no attempt has been made to trace the inheritance of either peculiarity, it cannot be determined how far sex may at first have limited, or may still limit, the influence of development. In like manner Mr. Catlin's statement respecting the grey hair of the Mandan Indians occurring (irrespective of age) in about one in ten or twelve of the whole tribe, and which he ascertained was "unquestionably an hereditary character which runs in families," is also defective, but it nay reasonably be inferred that the peculiarity in this race was chiefly characteristic of the males. $\$$

In plica polonica, a disease of the hair which is hereditary in Poland, Alibert\| states, that "it is observed not unfrequently to attack the father and the grandson, whilst the son is spared, a character (he proceeds to remark) which is common to it with other maladies, particularly with gout."

In cases of hereditary absence of hair, it is necessary to distinguish between those in which its development would be naturally limited to one sex, and those in which the hair is shared by both sexes alike. For example, in the justly celebrated story of Burnt $\mathrm{Njal}$, का the tragic occurrence, from which it derives its name, resulted from the feuds occasioned by Njal himself, nicknamed the " Beardless Carle," and his three sons, Skarphedinn, Grim, and Helgi, being taunted with their want of beard; and this hereditary absence of hair, peculiar to one sex, is well-known to characterize certain races of men, such as the North-American Indians, of the present day. As these cases could not be otherwise than limited to one sex, they are only indirectly connected with our subject by the fact of being hereditary. But there are many cases on record, in which the absence of hair common to both sexes, is hereditarily limited to one. In the case of a man at the late hospital of La Charité, in Paris, observed by M. Rayer, ${ }^{* * *}$ there was congenital deficiency of hair, so that the cranium appeared completely naked; " his mother and both his sisters had fine heads of hair, whilst his father presented the same defect in regard to the hair which

* Girou : op. cit., p. 123.

* Considérations sur la Nature et le Traitement des Maladies de Famille et des Maladies Héréditaires, troisième édition, p. 1, note 2. Paris, 1814. ‡ Lancet, Dec. 6th, 1862, pp. 619, 620 .

\$ Prichard: The Natural History of Man, p. 402. 1845. \| Op. cit., p. 40.

91 The Story of Burnt Njal, or Life in Iceland at the End of the Tenth Century. From the Icelandic of the Njal Saga. By George Webbe Dasent, D.C.L. 2 vols: 1861.

** Op. cit., pp. 1049-1050. 
he did himself." Danz* relates the case of a Jewish family in his neighbourhood, in which two adult sons neither have nor ever have had hair or teeth. In these cases it will be noticed that the baldness was both hereditary and congenital, but in the following cases the peculiarity was developed at a definite period after birth, showing, as often happens in hereditary affections, the associated influence of sex and age. The first is a case observed by Dr. Burgess, $\uparrow$ in which the baldness affected two brothers very early in life-" A young gentleman, eight years old, was brought to me (says Dr. Burgess) on the 4th of February, 1854, by his parents, with a shining scalp, as seen in old men, without a vestige of hair on it, denuded of eyebrows and eyelashes, and without hair on any part of the body. This boy had the usual supply of hair until he was four years old. The hair then began to fall gradually, until it totally disappeared. . . . . His brother, two years younger, began to lose his hair in detached places. His sister's, younger and older, have a good supply of hair, as have also his parents who brought him to me." In a case recorded by Poilroux, t three brothers became bald at the age of twenty-five years, and an uncle in their family had experienced the same loss at the same age. In a somewhat similar case referred to by Prosper Lucas, $\S$ all the sons became bald like the above at the age of twenty-five years, whilst the daughters preserved their hair. In the following case, related by Dr. Thurnam, $\|$ the baldness was congenital, but less complete than in the cases previously referred to - "A gentleman, aged fifty-eight, had been distinguished throughout life by the almost complete absence of hair, by the teeth being not more than four in number, by the delicate structure of the skin, and by the absence of sensible perspiration and tears; a cousin-german on the mother's side, who was born only a year or two before the subject of the preceding case, presented almost precisely the same peculiarities."

With respect to the preceding case, it is to be noticed that the association of peculiarities of the hair and teeth in the same individual is not uncommon, for it occurred also in Danz's case of hereditary absence of hair and teeth, and it is well known that a renewal of the hair in old age, of which there are many examples on record, is usually accompanied by a renewal of the teeth. IT The hereditary peculiarities of the teeth may therefore be conveniently considered after those of the hair. Some years since, I became acquainted with the case of a

* Stark's Archiv f. d. Geburtshülfe, Band iv. p. 684. Jena, 1792.

+ Manual of Diseases of the Skin : from the French of Cazenave, with Notes and Additions by Thomas H. Burgess, M.D. Second edition, 1854, note, p. 242 .

$\ddagger$ Nouvelles Recherches sur les Maladies chroniques: quoted by Prosper Lucas, tome i. p. 255.

\$ Traité Philosophique et Physiologique de l'Hérédité naturelle, \&c., tome i. p. 255, 1847 : quoted from Encyclopédie Méthodique, tome viii. p. 164.

\|I Medico-Chirurgical Transactions, vol. xxxi. pp. 71-82. 1831.

T This is still further illustrated by the late Lord Egremont's observation, that a preternaturally short lower jaw was always found in the white varieties of his red deer (cervus dama), in consequence of which they never lived more than a day or two, from not being able to press the udder in their attempts to suck. - Otto's Pathological Anatomy, translated by South, 1831, p. 183, note. 
gentleman abroad who had never had any teeth, and whose children inherited the same defect, but I did not secure a complete history of the case. Otto* refers to a case in which all the teeth were wanting in two brothers. Whilst, on the other side, Dr. Jacobi, $†$ of New York, cites a case in which three sisters were born with central incisor teeth. Deficiency of particular teeth has been occasionally noticed; and, according to Dr. Mason Good, $\uparrow$ " the absence of some of the teeth, such as the bicuspids, is not uncommon ;" but he considers that "it occurs more frequently in the incisors of the lower jaw ; and Mr. Fox (he goes on to inform us) refers to an instance in which this defect appertained to several individuals of the same family, none of whom had ever cut incisors of the lower jaw." One of the most curious cases of hereditary peculiarity of the teeth is the following, for which I am indebted to Dr. Cotton, and which affords a good illustration of atavism in connexion with the influence of sex. A gentleman had, with both dentitions, a double tooth in place of the left second incisor in the upper jaw; he was the only one in a family of nine children who presented this peculiarity, which he inherited from his paternal grandfather, whom he so exactly resembled, even in the form of the hands also, as often to have arrested the attention of their acquaintance. The influence of sex has been observed also in peculiarities affecting the colour of the teeth, for Professor Heider, of Vienna, has related a case in which teeth of a rose-red colour occurred in twins, the daughters of Italian parents; both the first and second dentition were marked by this peculiarity. $\$$ So likewise the hereditary tendency to caries of the teeth and toothache is sometimes limited, in a very decided manner, to one sex, as in the following case which occurred in my own practice, and in which complete limitation to one sex occurred for three generations. Mrs. A- - under the age of forty years, and the mother of seven children, has not had for many years a sound tooth, the decay having begun very early in life; she has no brothers, but there are three sisters, younger than herself, whose teeth are in a similar state, and in all of whom the decay commenced at a very early age; their mother was sinilarly affected in the teeth, and like her four daughters, was a "martyr to the toothache." Of Mrs. A-_'s seven children, five are girls, in four of whom, aged respectively sixteen, twelve, nine, and seven years, the teeth began to decay at the age of two years or soon afterwards; in the youngest girl, aged two years and a quarter, the teeth are not decayed, but the dentition has been difficult. Of the two boys, the third and fifth children in the order of birth, one died at the age of three years, and the other has attained the age of four years, without any decay in their teeth. The father of these children has sound teeth. Of Mrs. A-_'s three sisters, the eldest has four children, two boys, aged fifteen and five years, with sound teeth; and two girls, aged thirteen and three years,

* Loc. cit., p. $188 . \quad$ * American Medical Times, Dec. 15th, 1860, p. 418. $\ddagger$ The Study of Medicine, second edition, vol. i. p. 64 . 1825.

$\S$ Lancet, Dec. 6th, 1862, p. 637. 
with decayed teeth. The two other sisters of Mrs. A- have no children.

From special affections of the teeth we might readily pass to those of the eyes, for so intimate is the connexion which exists between the skin and its superadded structures, that peculiarities or defects of two or more parts are frequently associated in the same case; and as regards the teeth and eyes, Mr. White Cooper* goes so far as to state, that in all cases of double microphthalmia brought under his notice, he has, at the same time, met with defective development of the dental system. Before, however, leaving the mouth, it will be useful to notice some cases of hereditary hare-lip limited in like manner by sex, some of which are also associated with lachrymal affections, and may therefore appropriately precede the consideration of special defects of the eye hereditarily limited to one sex. M. Demarquay, $t$ in a paper on hair-lip, published in 1845 , called particular attention to the influence of hereditariness in the production of this deformity; and from among the cases he has recorded may be cited that of Eliza Dif, affected with double hare-lip, whose mother had simple hare-lip. In another case, a carpenter and his son were affected with hare-lip; in another, a mother and her daughter were similarly affected; and, lastly, in the case of a young man operated on by M. Thierry for this deformity, it was ascertained that the father had been previously operated on for the same by M. Desault. In the case of a boy with simple hare-lip, operated on by M. Roux, $\neq$ a brother had been previously operated on for double hare-lip. In another case of M. Roux's, of a father and son with six fingers on each hand, and six toes on each foot, there was also double hare-lip in both. M. Rouxई used to cite in his clinical lectures the case of a peasant of Seine and Oise, on whom he had operated for a double hare-lip, and who was at the same time affected with ectropium of the two superior eyelids; his son presented exactly the same departure from nature. Whilst the atavic inheritance of the defect is shown in the following case quoted by Prosper Lucas :|| "A man well formed, among the parents of whom were found two attacked with hare-lip, had by a first wife eleven children, two of whom had hare-lip; and by a second wife, two who were affected with the same deformity."

The following cases of hereditary disease, and defect of the eye and ear, may be added to those previously cited, as illustrating still further the extent to which the influence of sex prevails. In a case of cataract observed by Duval, 9 four sisters, their mother, and grandmother were similarly affected. Prosper Lucas** relates the following case of hereditary blindness limited to the female sex for three generations: "The grandfather had excellent eyes, the grandmother was attacked with

* Ophthalmic Hospital Reports, vol. i. pp. 112-13. 1857-9.

+ Gazette Médicale de Paris, Jan. 25th, 1845.

‡ Gazette des Hôpitaux, Jan. 29th, 1846.

ई Referred to by Deval : Traité Théoretique et Pratique des Maladies des Yeux, p. 89.1862.

॥ Op. cit., tom. ii. p. 36. $1850 . \quad$ T Quoted by Deval: op. cit., p. 89. ** Op. cit., tom. i. pp. 400-1. 
amaurosis at the age of thirty-five years; her daughter (married) became blind at nineteen - she has had seven children, the eldest, a girl, became, from amaurosis, blind at thirteen ; the second, a daughter also, became amaurotic at the same age as the preceding; of the last four children, one, a daughter, died at the age of two years, and another, also a daughter, is aged thirteen years, both free from the disease ; the other two children are boys, one three years, the other scarcely one yèar, seeing well." In a case observed by Deval,* a young man, his father, and two uncles, were amaurotic, a sister had amblyopia: in this case it is to be noticed, that as the father and two uncles were similarly affected, the inheritance was probably derived by direct or by interrupted descent from a previous generation. In a case of hereditary amaurosis observed by Graefe, $t$ three sons were successively affected about the age of twenty years, their father having been myopic ; and in another case which came under my own observation, and which has been already published, + five brothers and their paternal uncle were amaurotic, whilst their three sisters had no imperfection of sight; in this case also it may be inferred that the inheritance was derived from a previous generation, and transmitted by interrupted descent. Among the cases observed by M. P. A. Dufauई are congenital amaurosis in two brothers named Clapos, and in two brothers named Caffet; congenital cataract in a young man named Croiset, whose grandfather, and a first cousin of the male sex, also had cataract; and a case of amaurosis in a family of three sisters, named Baudissou. Mr. Critchett $\|$ has observed a case of nuclear congenital cataract in three brothers. In a case of coloboma iridis, for which I am indebted to Mr. Ernest Hart, the defect was limited to two sisters, who belonged to a family of three children, in which the intermediate child was a boy, free from the defect. Mr. Zachariah Laurence lately showed me a well-marked case of hypermetropia, affecting a father, and his son aged seven years. DevalT relates a case of troublesome affection of the left eye in a.woman whose mother, two maternal aunts, and maternal grandmother were the subjects of lachrymal affections. In the following case, observed by Stahl,** we have an illustration of the inheritance of accidentally-acquired defects of the eye : "A soldier lost in war one of his eyes; he returned to his country and married ; his wife bore him a son, one of whose eyes was quite dried up, so that he was monoculus like his father." Lastly, in the curious case of colour-blindness observed by Deval, $+\uparrow$ we have an illustration of an hereditary defect, sexually limited, and in most

* Op. cit. p. 89.

+ Archiv für Ophthalmologie, tom. iv. part 2: quoted in Annales d'Oculistique, tom. xlv. pp. $187-8.1861$.

¥ Medical Times and Gazette, March 22nd, 1862, p. 309.

$\S$ Essai sur l'Etat physique, Moral et Intellectuel des Aveugles-nés, \&c. Paris, 1837 .

\|l Ophthalmic Hospital Reports, vol. iii. p. 339. 1860-1.

Tा Op. cit., p. 89.

** Quoted by Steinau: Essiay on Hereditary Diseases, p. 30. 1843. t+ Op. cit., pp. 607-8. 
other cases apparently congenital,* but in this case developed in after-life during the progress of disease: "Under the influence of an attack of hemiplegia and double amblyopia, supervening on the sudden suppression of a skin disease, Poiré, a clock-maker, and longsighted, who had been under treatment in 1850 , lost the power of discerning red, and the madder coloured trousers of soldiers appeared to him to be yellow; other colours were, however, perfectly distinguished; curiously enough his father had never been able to distinguish red. Our patient, adds M. Deval, was then hereditarily predisposed to colour-blindness, but a cause capable of disturbing the visual functions was needed for this symptom to take its place among the amaurotic phenomena developed."

With respect to defects of the organ of hearing, I have lately had under observation the case of a surgical-instrument maker, aged twenty-nine years, who became deaf, like his father, at the age of eighteen years; there were five other children in the family-namely, a son, who died at the age of seven years, one son and a daughter above, and one son and a daughter below the age of eighteen years, none of whom have ever had any defect of hearing. Dr. Camps has informed me of a case occurring in his practice, of nervous deafness affecting a father and son. In a case for which $\mathrm{I}$ am indebted to $\mathrm{Mr}$. Anderson Smith, a woman six months after marriage had an attack of fever, followed by permanent deafness; of four children born subsequently, one of them, being the third in order of birth, and a daughter, is a deaf-mute, whilst the other children, who are sons, hear well. Prosper Lucast records the case of a female cat, born deaf, and among many kittens that she had, was a female one, also deaf like the mother. In addition, also, to the illustrations of deaf-muteism previously cited, may be added the case observed by Portal, $\$$ of three sisters who were deaf-mutes; and although it is generally difficult to trace the occurrence of this defect to any hereditary source, yet its occasional development in connexion with atavism leads to the supposition that it is at least sometimes hereditary; for, in addition to Mr. Wilde's evidence already quoted, $\S$ Meckel|| relates that a woman, herself enjoying perfect health, but in whose family there had been many members attacked with hardness of hearing and idiocy, gave birth to two sons who were deaf-mutes, and two danghters and one son who were not so. Whilst the following case, observed by Mr. Anderson Smith, affords a good illustration of hereditary defect of the external structure of the ear: a married woman, who had rudimentary ear-lobules adherent to the head, has had five children, consisting of two sons and three daughters: one son deceased, and one daughter, have not been examined; the living son has the ear-lobules pendulous and wellformed, like those of his father, and two daughters have rudimentary

* For cases of non-congenital colour-blindness, see Arch. f. physiol. Heilk., 1858, p. 41 ; and Gaz. des Hôp., 1861, p. 450.

$\uparrow$ Op. cit., tom. i. p. 428.

$\mp$ Op. cit., p. 8.

$\S$ British and Foreign Medico-Chirurgical Review, July, 1861, pp. 200-1.

\|l Archiv für Anatomie, p. 186. 1828. 
and agnate ear-lobules, like their mother; they are both married, but one has no issue-the other, whose husband has ear-lobules of natural size and pendulous, is the mother of three children, one of whom is a son with ear-lobules resembling those of the father, and two are daughters, both of whom have rudimentary and adherent ear-lobules precisely like those of their mother, maternal aunt, and maternal grandmother.

Before leaving the diseases and defects of the skin and its dependencies, it may be useful again to direct attention to the frequency with which they are connected together in the same individual; for not only has this been observed with respect to colour-blindness combined with inability to distinguish musical notes, as well as in several other examples of associated disease of these structures already referred to, but it has also been noticed in many other cases, from which the following may be selected as illustrations. M. Liebreich* has observed that "when deaf-muteism and pigmentary retiuitis were developed in the same family, the two affections were constantly conjoined in the same individual." M. Bonvyer-Desmortierst relates the particulars of "a family of Angora cats, of which the mother is white and deaf; the father, which hears, is white and black; all the kittens which are born white are deaf as the mother; those which resemble the father are not so." The connexion which exists between the organ of hearing and the hair corresponds with the following case observed by Dr. Pauli, $\neq$ in which the defect in the organ of hearing is replaced by defect in the organ of sight:- "Rudolph Median and his wife, endowed with a normal conformation, had nine children, all born blind; the father has black, and the mother light-coloured hair; five children, with dark hair and brown iris, are afflicted with amaurosis; the four others, provided with light-coloured hair and blue iris, have amaurosis and cataract conjoined." Many other illustrations of these associated defects might be cited, but the above are sufficient to show that hereditary affections of the skin and its dependencies, under which term have been included not only the ordinary appendages of the skin, but also the organs of special sense, have not been abruptly brought together, but are naturally more or less closely related, and that this relationship sometimes becomes very conspicuous in sexually limited and hereditary disease of these structures.

It may now be convenient to consider some of the hereditary peculiarities and defects of the upper and lower extremities, in which the influence of sex has in like manner been observed to prevail, and which are of not unfrequent occurrence in families, although not always noticed by medical writers; for some of them are very erroneously thought to be of too trivial a character to be recorded, and the mention

* De la prédisposition à la rétinite pigmenteuse chez les enfants-nés d'un mariage entre consanguins: Archives Gén. de Méd., Février, 1862, pp. 145-151. (Extrait de la Deutsche Klinik, 1861, No. 6.)

t Considérations sur les sourds-muets de naissance, in 8vo, an. vii. p. 123.

$\mp$ Quoted by Deval, op. cit. p. 89 . 
of many others is purposely suppressed. Portal* refers to cases in which the bones of the arm, the fore-arm, the thigh, or the legs, are out of proportion with the rest of the body, but of which he "suppresses examples, so as not to displease families;" and I have been privately informed of some interesting cases of hereditary defects of the extremities, in which the history has been withheld, from an over-sensitive reserve on the part of the family affected. Whilst in some of the lower animals - as, for example, in insects-supernumerary limbs and parts of limbs, such as three legs attached to one coxa, and other curious anomalies, appear to be of rather frequent occurrence, although hereditariness in such cases necessarily cannot be established. $†$

As an illustration of the influence of sex in hereditary defects of the upper extremity, I would refer to the case observed by Dr. Pauli, $\neq$ of hereditary brittleness of the bones, which seems to have affected chiefly, if not exclusively, the bones of the upper extremity for three generations; three members of the last generation had broken an arm twice, and one thrice; their father and grandfather had both in like manner suffered from fractures. Some years ago, a man was exbibited at the Academy of Sciences (Paris), whose hands were of a monstrous size, and whose father's were equally large. $\$$ And the same regularity in the limitation of such defects to one sex may occur also in those cases in which the defect itself is not symmetrical as regards the two sides of the body, as in the case related by Portal, $\|$ " of a father and two sons, who had the left side of the body, with respect to the muscles, much larger than the right, they therefore used the left side and limbs more frequently than the right, and were of course left-handed. Girou 9 relates the case of a man, descended from a family in which the special use of the left hand was hereditary; although not himself left-handed, he has a married daughter who is so, and all of whose children are left-handed; he has, moreover, a son married, who is not left-handed, but who is the father of a daughter so completely left-handed from her cradle, that it has been necessary to tie up the left hand, so as to force her to serve herself with the right hand; in this case the influence of sex appears to account for the atavic inequality of the descent. Mr. Joseph Adams** refers to the case of an Irish mendicant scholar with a deformity of the hand,

* Op. cit., note, p. 17.

* Dr. Herrmann Asmuss : Monstrositates Coleoptorum. Rigæ et Dorpati, 1835.

‡ Untersuchungen, und Frfahrungen um Gebiete der Chirurgie. Leipsic, 1844. (Quoted in the British and Foreign Medico-Chirurgical Review, vol. xxii. p. 49. 1846.)

\section{$\S$ Portal, op. cit. p. 18.}

$\|$ Op. cit. p. 20. As other examples of this want of symmetry in deformities hereditarily limited to one sex will be referred to in speaking of the fingers and toes, it will be sufficient to state here that such unsymmetrical malformations occur in all parts of the body, and are sometimes very limited in their extent, and very conspicuous in their appearance, as in the case related by Portal (pp. 20-1), of a Spanish nobleman, who had one cheek bigger than the other; his father and some of his uncles had the same peculiarity.

Tा Op. cit., pp. 278-9.

** A Treatise on the supposed Hereditary Properties of Diseases, \&c., p. 68. 1814. 
which was "an exact resemblance to his father's." In a case, previously quoted, of hereditary absence of the two distal phalanges, ${ }^{*}$ the transmission of the defect for ten generations had been affected by the females only of the family. A similar defect occurred to a less extent for three generations in the family of a pastrycook at Douai, + named Augustin Duforet, who had but two phalanges to all the fingers, the first being nearly double the length of the ordinary phalanx, and the last or ungual of the normal form and length; the thumbs having each two phalanges, but no metacarpal bone; the toes, likewise, with only two phalanges, as well as the great toes, which were without the metatarsal bone: his grandfather was similarly constituted, and he had three children all similarly malformed; the eldest, of the male sex, had three male children, all of whom wanted the phalanges of their fingers and toes; the second, of the female sex, has had five children, two daughters who have three phalanges, and three sons who have only two; the third, who is the father of Augustin, has had eleven children, five danghters normally formed, and six sons, in all of whom there is wanting a phalanx to the fingers and toes; the mother of Augustin has had two miscarriages, in which the fotus was both times of the male sex, and equally wanting in the phalanx of the fingers and toes. In the above case the defect was proved to be hereditary for three generations, and although one exception to sexual limitation occurred in the second generation, it is to be noticed that in the third it was complete, for of nineteen grandchildren, twelve were sons, all born with the family defect, and seven were daughters, all born free from it. In the case observed by Dr. Lepine, of Chalon-sur-Saône, * of a man who had only three fingers on each hand, and four toes on each foot, both his grandfather and his son had the same anomaly. But it must be admitted that in many cases of deformity affecting the extremities no strictly-defined limitation of this kind is maintained, although the influence of sex can generally, to a certain extent, be traced in most of them; as, for example, in the following case observed by Béchet,§ of a woman (Victoire Barré) who, instead of hands, had on each arm one finger only, the other fingers and their metacarpal bones, with the exception of imperfect rudiments of two of the latter, being entirely wanting; whilst on each foot there were but two toes, apparently the first and fifth, but both very defective: she was twice married; by her first marriage she had a healthy and regularly-formed male child, and by her second marriage two daughters malformed like herself; and her sister and father were also deformed in a similar manner. In this case it is probable that the father inherited and transmitted the defect from a female ancestor of some previous gene-

* Edinburgh Medical and Surgical Journal, vol. iv. p. 252. 1808.

+ Des Vices congenitaux de conformation des Articulations (Thèse). Par Alf. Robert. Paris, 1851, pp. 167-8 (quoted in the Bulletin de la Soc. Anat. 1838, p. 35.)

¥ Bulletin de l'Académie Royale de Médecine, séance du 31 Octobre, 1843, tom. ix. p. 145 .

\$ Essai sur les Monstrosités Humaines, 1829: quoted in the Lancet, 1829-30, vol. i. pp. 791-2. 
ration; and it is also to be noted in reference to these cases, that owing to the occasional intermarriage of persons similarly malformed, exceptional illustrations may, in some rare instances, be referred to a double inheritance of the defect, as in the case observed by Piorry,* at Clamart, in 1840, of a person in whose hand one finger was wanting, both the parents having equally but four fingers on the hand: whilst in Dr. Horace Dobell's ${ }^{\dagger}$ case of hereditary malformation of the hands in two cousins who married, but whose offspring was free from the defect, it may be inferred that it will, in consequence of this temporary suppression, reappear in a succeeding genneration, for in the most strongly-marked forms of hereditary disease, uninterrupted descent for several successive generations is the exception rather than the rule, and the freedom of the offspring in his case is probably due to the fact that by the consanguineous alliance of persons similarly malformed, the defect itself has been rendered more hereditable, owing to which the immediate offspring had not been malformed, because it had been reserved to transmit the malformation by atavic descent.

The fingers, and especially the little fingers, may be more or less deformed without absence of any of the phalanges. A well-marked case of this description has lately come under my notice, in which a journeyman cabinet-maker, aged thirty-one years, has the little fingers so crooked and bent inwards as to constitute a well-marked deformity; of his children, the first, the second and third (twins), and the fifth are boys, with exactly the same malformation of the little fingers as their father; the fourth child is a girl, with the little fingers straight and well-formed, like those of her mother. In the following remarkable case, noticed by Gaubius, $\ddagger$ a corresponding defect in the little finger, which was also hereditary in the male line, was not congenital, but developed in after life:- "The little finger of a man began, from some cause or other, to grow inwardly, and became quite bent towards the palm of the hand; the eldest of his two sons, when at the age at which his father became affected with the deformity, observed that his little finger began to bend towards the palm; different remedies were applied, but in vain; the second brother, fearing the same fate, began, long before the fatal period, to use all possible preventive means, but without effect; at the same period his little finger bent, like that of his father and his brother." In the following case, observed by Blumenbach, § a similar deformity, though acquired by accident, and limited to the little finger of only one hand, in like manner affected

* De l'Hérédité dans les Maladies, p. 46. Paris, 1840. In connexion with hereditary deficiency of the fingers, it may be remarked, that when Captain Cook visited the Friendly Islands, he found scarcely one in ten of the Islanders who was not deficient in the little finger of one or both hands. This, however, did not proceed from any hereditary defect, but from the curious custom they had of cutting off the little finger in sickness as a sort of sacrifice to the Deity, "efficacious enough to procure the recovery of their health."-Captain Cook's Voyage of Discovery, edited by John Barrow, Esq., F.R.S., p. 385 . Edin. 1860.

+ Royal Med.-Chir. Society, Nov. 25th, 1862.

¥ Quoted by Steinau, op. cit., pp. 27-8.

§. Quoted by Prosper-Lucas, tom. ii. p. 493.

62-xxxI. 
the males for two generations: " a man, whose little finger of the right hand had been nearly demolished and set awry, had several sons, all of whom had the little fingers of the right hand crooked."

Lastly, the same influence of sex is sometimes to be noticed in cases of supernumerary fingers, which are usually, though not always, associated with a corresponding excess of toes. In a case of this description, in which a supernumerary finger was attached to the outside of the first phalanx of the little fingers (admitted into Long Island College Hospital, America)," the deformity had occurred for five generations, and it is quoted to show the influence, rather than the complete limitation, of 'sex in such cases : the patient was the fourth child of the same parents, all having these supernumerary fingers, except the second; the first child had but one, and the third child had two supernumerary fingers. The mother had one attached to the same point as those of her children; the grandmother had two, and the great-grandmother also two; the grandmother's brother had supernumerary fingers on each hand, as also had one of his nephews; the great-grandmother states that her father had the same deformity." In the above case it is to be noticed that the deformity was inherited five generations back from a male ancestor, who had transmitted it to a son and a daughter, and it is at this point in the descent that the influence of sex becomes apparent ; for whilst on the one side it affected only the son and one of his nephews, and was so far limited to the male sex ; on the other side, it continued in direct female descent for four successive generations. In a somewhat similar case, lately reported to the Swedish Medical Society by Dr. Rörberg, $†$ two brothers, themselves as well as their parents free from deformity, had each two children with supernumerary fingers attached to the metacarpal bones of the little fingers, and also supernumerary toes. So also in the case of a French lady (Madame D_- ) and her sister, both free from deformity themselves, but some of whose children had supernumerary fingers or toes. Madame D - had twelve children, nine sons and three daughters; two of the younger sons had supernumerary toes, and the eldest son, free from the deformity himself, had six children, of whom one had an additional toe; none of the daughters of Madame $\mathrm{D}$ - had supernumerary toes, but one of them had a supernumerary finger; whilst the sister of Madame $\mathrm{D} \longrightarrow$, who also had several children, had one with a supernumerary toe. ${ }^{+}$And in a case for which I am indebted to Mr. H. Scholfield Johnson, of a double last phalanx, slightly webbed, equal in size, and with well-developed nails, on the left thumb of a boy, the maternal grandfather's great-nephew had exactly the same deformity. Such cases as these possess an additional interest, as examples of what may be assumed to be remote atavism ; and although it must be acknowledged that the influence of sex is less strongly marked in these than in many other hereditary

* Medical Times and Gazette, Dec. 22nd, 1860, p. 619 (quoted from the American Medical Times, No. 16).

† Journal für Kinderkrankheiten, Band xxxv. p. 426. $\ddagger$ Medical Gazette, 1832-3, vol. i. p. 361 . 
defects, yet it can generally, to a certain extent, be traced. Two daughters of Caius Horatius* had six fingers on each hand. In a case recorded by Roux, $\uparrow$ of a father and son who both had six fingers on each hand, and six toes on each foot, the defect was associated in both of them with a double hare-lip. In the following case, which has come under my own observation, and in which there was a complete supernumerary finger with nail attached to the outer side of the first phalangeal joint of the little finger of the left hand, the influence of sex, although not at first sight apparent, may be readily perceived on reconsidering the case : the patient was a girl aged six years, the only child affected in a family composed of one daughter and three sons; the father, paternal grandmother, and paternal aunt, had precisely the same deformity; three paternal uncles and two paternal aunts were free from it, and two of the former have each two daughters and one son also free from the defect. The influence of sex, although incomplete in this case, is still shown by the fact that the grandmother's defect was in the third generation transmitted to the granddaughter, but not to any of the grandsons; whilst in the second generation, in addition to its direct transmission to a daughter, the son, who was selected to become the medium of its transmission to the granddaughter, partook also of the inheritance.

In like manner many cases of hereditary webbing of the fingers exhibit the influence of sex in their development, even when the heritage has become much involved, as in the case of a web-fingered family recorded by Mr. J. B. Thompson, of Perth, $\ddagger$ who concludes his observations on the case by stating, that "we have in it a grandfather, a father, and an uncle sending down an abnormal condition directly through the male line " and on the other hand, "we have a grandmother and a granddaughter transmitting the same directly to their children."

The following cases may be cited as illustrations of the influence of sex in hereditary defects of the lower extremity. In the case observed by Dr. Maissiat, of a fruit-seller at Mantua, named Margaret Gardes, suffering from spontaneous luxation of the thigh, the same affection has been traced through five generations of the family. Among the ascendants of Margaret Gardes, two maternal aunts and one grandaunt (maternal grandfather's sister), were lame from infancy; and another grand-aunt, sister to the above, though not herself affected, had a child with shortening of the right lower extremity: among the descendants of Margaret Gardes was a daughter, named Limone, who had congenital shortening of the thigh to the extent of about three inches; she married a man, himself well made, but whose grandfather had a double congenital luxation of the thighs ; four children resulted from this marriage, one of whom, a girl, had congenital luxation of

* Pliny, Hist. Nat., lib. vii. cap. 11.

* Gaz. des Hôp., 2 série, tom. viii. p. 46.

‡ Edinburgh Medical Journal, 1858-9, pp. 501-4.

§ Dupuytren on Original Luxation, of the Femur: Medical Gazette, 1833, vol. ii. p. 570 . 
both thighs, and another child, a boy, had congenital luxation of the left thigh. It is to be noticed, in connexion with the above case, that congenital luxation of the femur is more common in females than in males; for Dupuytren, who quotes the above case, states, that out of twenty-five or twenty-six cases which had come under his notice, he had not met with more than three or four examples of its occurrence in male infants ; consequently, the females in Margaret Gardes' family would be more liable than the males to suffer from this affection; but the influence of sex in this case is very strongly exhibited in the results of the intermarriage with a family in which the luxation was in the male, for one of the offspring affected in the fifth generation was a boy, who seems to have derived the morbid inheritance from his paternal grandfather by atavic descent. Venette* relates a case of a wornan and her daughter who both had a sort of limp in the right leg. Mauriceant relates a case of a lame man having had three sons who were all lame. "Borelli, quoted by Rougemont, records the case of a well-made man, who was three times married, and whose father had been lame; the children of this man by his three wives were all lame." +

In passing downwards from the hip to the knee, those cases come under notice in which the patellæ are hereditarily absent. This occurred in the case of a man who was a patient in St. George's Hospital in $1833, \S$ and in whom both the patellæ were entirely wanting; neither his grandfather nor his father had ever had patellæ. In a similar case, which Sir Henry Holland informs me he had the opportunity of seeing in private practice, and which is referred to in his 'Medical Notes and Reflections,' absence of the patella occurred in father and son.\|

Similar evidence respecting the influence of sex sometimes presents itself in connexion with club-foot, as in the case of Madame B-, related by Girou, वा which is of additional interest as an instance of atavism restricted to the females by transmission through a male: this lady, who was herself club-footed, had three male children perfectly well formed; the eldest of these married, and had, at first, six sons well formed, and afterwards four daughters, one of whom was club-footed like her paternal grandmother. And lastly, as regards webbed toes, Mr. Joseph Adams** relates an instance of its hereditary transmission for two generations from father to son; and Dr. Watsont records the case of a musical composer of some celebrity in London who is web-footed, "and whose father, grandfather, and great-grandfather were all web-footed before him."

From diseases affecting distant parts of the body, we may now pass to those affecting the three great centres of life-namely, the brain,

* Génération de l'Homme, tom. ii. ch. 7.

+ Quoted by Steinau, op. cit., p. 27

$\S$ Medical Gazette, Jan. 19th, 1833, p. 518.

\| Medical Notes and Reflections, third edition, 1855 , p. 33.

of Op. cit., p. 279.

** Op. cit., p. 68 .

t+ Lectures on the Principles and Practice of Physic, third edition, 1848, vol. i. p. 109. 
the heart, and the lungs, in all of which similar, though in some respects less conclusive, evidence of the influence of sex will be observed.

With respect to the large class of cases which may be massed together as cerebral diseases, it is proposed to offer first a few general remarks on the evidence derived from statistics and general observations on hereditary insanity, as influenced by sex, and then to consider the evidence afforded by special cases of cerebral diseases, which, for convenience, have been arranged as far as possible in separate groups.

It has been satisfactorily proved, that in many of the diseases which have already been considered in some detail, sex has influenced, to a great extent, their development; and in some of them it has had the effect of altogether restricting the disease to one line in a family, to the exclusion of the other-as in colour--blindness, and the hæmorrhagic diathesis, and to a very marked, though a less extent, in many other diseases. It may therefore be reasonably assumed, that the same influence of sex extends also to cases of cerebral diseases; and as regards more particularly insanity, it is especially important to ascertain whether a disease so often observed to be hereditary, and so much dreaded as this is, admits of any corresponding limitation in its development.

Among writers who have directed special attention to the hereditariness of insanity is Esquirol,* who states, that it "is more often transmissible by the mothers than by the fathers ;" and this fact he ascertained "by attending, in the last years of his life, the children of those patients whom he had seen at the beginning of his medical career." This statement seems to be very generally admitted to be correct, and it is supported by the statistical researches of M. Baillargert and Dr. J. Webster, + which moreover show that insanity is not only more transmissible by females than by males, but that from whichever parent the heritage is derived, it is more liable to show itself in the children of the same than of the opposite sex. M. Baillarger ascertained that insanity is more to be feared when it is on the mother's than on the father's side, "not only because it is more often hereditary, but also because it is transmitted to a greater number of children "' and from his observations, founded on 600 cases, 453 of which were directly hereditary, and 14.7 collaterally so, he states that where the madness was transmitted direct from parent to child, the following statistics were obtained-

"Of 346 children who had inherited the disease from the mother, I have found-

$$
\left.\begin{array}{r}
197 \text { girls } \\
\text { and } 149 \text { boys }
\end{array}\right\} 346
$$

The difference is 48 , or a fourth.

* Des Maladies Mentales, p. 65. 1838.

* Archives Gén. de Méd., Paris, 1844, quatrième série, tom. v. pp. 116-17; and Annales Médico-Psychologiques, tom. iii. 1844, pp. 328-339.

$\ddagger$ Medico-Chirurgical Transactions, vol. xxxii. p. 118.1849. 
"Of 215 children to whom the disease had been transmitted by the father, I have found-

$$
\text { and } \left.\begin{array}{r}
128 \text { boys } \\
87 \text { girls }
\end{array}\right\} 215
$$

\section{The difference is 41 , or a third.}

"The madness of the mother is transmitted, then," adds M. Baillarger, " more often to the daughters than to the sons, in the proportion of a fourth; the madness of the father, on the contrary, more often to the sons than to the daughters, in the proportion of a third."

Dr. J. Webster states, from observations founded on 1798 cases of insanity, that it " is a disease more frequently transmitted to offspring by the mother than by the father; whilst mothers also transmit this disease oftener to their female than male children."

More recently, Dr. Moreau, physician to the Bicêtre (hospital for the insane), in a paper "On the Signs indicative of Hereditary Predisposition to Insanity"* which confirms the general correctness of the preceding statements, has endeavoured to show "that personal resemblance and cerebral disorder may be transmitted by either parent, but never by the same;" that where the children resembled the parent of the opposite sex, the following results were obtained: "Of 22 females suffering from insanity, 17 had inherited it from the mother, and 5 from the father; while of 142 insane males, 95 had acquired the disease from the father, and 47 from the mother; when, on the contrary, the analogy of resemblance was. inverted, 47 sons who resembled their father derived their insanity from the mother, and 8 girls who resembled the mother derived theirs from the father." These observations of Dr. Moreau seem to possess some interest and importance in connexion with atavism, and may be again referred to, but at present it will be convenient to examine the evidence which can be gathered in favour of the influence of sex in special cases of cerebral disease.

With respect to cases of hereditary insanity limited to males, the following illustrations may be cited. In a case observed by Moreau $\dagger$ at the Bicêtre, the grandfather, father, and son were all insane. The hereditary madness which occurred in the case of Louis XI. of France, is referred back by Moreau $\ddagger$ to his paternal great-grandfather, who had been poisoned in his youth, and who ever afterwards remained invalid; his grandfather, Charles VI., suffered from periodic mania; and his father, Charles VII., died from excessive abstinence, resulting from a delusion that he should be poisoned. In the case of Papavoine, $\S$ aged forty-one years, who murdered two children in 1825 , his father had suffered from periodic mania. In the case of James Roberts, $\|$ a soldier who had served in the Crimea, and who was tried lately at the

* I'Union Médicale, No. 48.

+ Un chapitre oublié de la Pathologie Mentale: L'Union Méd., Jan. 26th, 1850, p. 45 .

‡ La Psychologie Morbide, p. 557. Paris, 1859.

\& Georget: Archives Gén. de Méd., tom. viii. p. 206. 1825.

II The Times, Aug. 19th, 1862. 
Oxford assizes for the murder of his little daughter, Clara Roberts, aged sixteen months, by beating her upon the head with a broken poker during a sudden attack of homicidal monomania, and was acquitted on the ground of insanity, his father, paternal grandfather, and paternal grand-uncle had all been insane; and it is to be noticed in this case, that as the paternal grandfather and paternal grand-uncle were brothers, the inheritance of the disease was probably derived from a previous generation. Such also may be inferred in the case of a military surgeon* confined in the Bicêtre, whose father, eldest brother, and four paternal uncles were also insane, the uncles having, besides, all died by suicide; the maternal line was ascertained to be free from all nervous affection. No history of the paternal grandfather could be obtained in this case; but as five of his sons were mad, it is probable that if not himself mad, he transmitted insanity to his male offspring by atavic descent, which would extend the heritage to four, if not more, generations, such interruptions in morbid descent being of frequent occurrence in insanity. Marct relates a case in which a grandfather and grandson died mad with the same symptoms of insanity; the celebrated author of 'Paul and Virginia' often believed himself to be surrounded by enemies and evil spirits, and his grandson suffered from the same delusions; + and if it were not for the difficulty of tracing the family histories of individuals comparatively obscure in social position, it is probable that such cases of hereditary madness would be more frequently recorded; for in the well-known case of George III., which will be again referred to in a subsequent part of this paper, the insanity was transmitted in the male line by atavic descent from a male ancestor eight generations back, in whom not only the insanity, but many other of the well-known characteristics of the unfortunate monarch were exactly repeated.

In all of the preceding cases the insanity has been limited to the male line, but the same influence of sex prevails also when females become hereditarily subject to the disease. In one of the cases recorded by Moreau, $\$$ a mother and her daughter believed themselves to be under the special protection of spirits, which they called "airs." A case is recorded in the 'Annales Médico-Psychologiques' for 1850, pp. 723-4, of a mother and two daughters who were insane. M. Villermé $\|$ relates a case in which a mother and daughter were insane, the son not so. Gintrac 9 records a case of insanity in a woman whose mother had suffered from puerperal mania; and another case of a woman, aged twenty-six years, subject to delusions, whose mother had twice attempted suicide; the father was healthy, and there were five other children who were all well. In the case of Mrs. Vyse, who was lately tried for the murder of her two children, and had also attempted

* Moreau : La Psychologie Morbide, pp. 138-9.

† De la Folie, Observ. 45. Paris, 1840.

¥ Moreau : La Psychologie Morbide, pp. 538-9.

$\S$ L'Union Médicale, Jan. 12th, 1850, p. 22.

\|l Revue Médicale, tom. vi. p. 98. 1821.

T Mémoire sur l'influence de l'Herédité sur la production de la surexcitation nerveuse, \&c. : L'Académie Royale de Méd., Mémoires, tom. ii. 1845. pp. 276-7. 
suicide, the acquittal was given on the ground of hereditary insanity, for her maternal grandmother and maternal graud-aunt were both insane, and the former had also attempted suicide, whilst the latter had been under restraint for twenty years. In this case it may be inferred that as these two fernale ancestors were sisters, the insanity had been transmitted from a previous generation, for whenever two or more members of the same family are similarly affected, especially with insanity, which has, moreover, been transmitted to a succeeding generation, it may be assumed that the disease has in the greater number of such cases been inherited, unless it has resulted from some other recognised cause of disease-as, for example, the repeated intermarriage of blood relations. In a case of puerperal insanity affecting one of my patients after her first accouchement, at the age of twenty-eight years, and continuing for seven months, it was ascertained that an elder sister, now aged fifty-one years, had become insane at the age of twenty-one years, and had continued so ever since, with short and imperfectly lucid intervals; three brothers and four sisters older than the patient referred to are all married, and most of them have children, but none of them have exhibited any tendency to insanity at any period of their lives. It is probable that the insanity in these two sisters was inherited from a previons generation by atavic descent, for many similar examples are recorded in which it is almost impossible to doubt that such was the case, as in that observed by Moreau* at Charenton, of two sisters who suffered from the same form of monomania, believing themselves to hold intercourse with spirits; in the case, also observed by Moreau, $\dagger$ of two monomaniac sisters, who both fancied that Charles $X$. was in love with them; in the case of two brothers, twins, confined in the Bicêtre on account of monomania; and in the remarkable case recorded by Moreau, $\neq$ of a gentleman of good position in society, who was the survivor of six brothers who were all mad. In all such cases as these it may be inferred that the insanity was transmitted from an insane member of some previous generation, and probably of the same sex; and in the event of there being no wilful concealment of facts, it may be assumed that the interruption had extended over so long an interval of time, that no record of the descent, such as happened to be historically preserved for more than two centuries in the case of George III., can be procured.

On the other hand, cases occasionally occur in which, through the influence of what may be called insane alliances, both parents, if they do not inherit, at least transmit, the disease. Some remarkable examples of this have from time to time been recorded, such as that which occurred some years ago in Brittany, in which a whole family, composed of father, mother, son, and daughter were insane; $\$$ and in the case observed by Dr. Burrows, $\|$ of a young man belonging to a

* L'Union Médicale, Jan. 12th, 1850, p. 22. + Ibid.

¥ La Psychologie Morbide, p. 140, note.

$\S$ Gazette des Tribunaux, Fév. 3, 1828.

II Commentaries on the Causes, Forms, Symptoms, and Treatment, Moral and Medical, of Insanity, p. 104. 1828. 
Jewish family, who, with his father, mother, and six brothers and sisters, were all mad. The influence of sex in these cases may have been maintained, but it could not of course be traced.

With respect to cases of hereditary suicide as distinguished from the preceding, Falret* states that he has established a great number of times the fatal effects of hereditary predisposition in suicidal melancholy ; and Cazavieilht ascertained that in eighty-one cases of suicide occurring in a limited portion of the department of the Oise (France), hereditary influence was shown to occur twenty-two times; that it appeared nine times in the direct line, seven times between brothers, five times between uncle and nephew, and once between cousins.

It is necessary to state also that self-destruction is more common in males than in females; this is shown to be the case by statistics obtained not merely from different countries, but also at different epochs, a precaution needed in consequence of the curious and somewhat unaccountableł manner in which epidemics of suicide, also limited by sex, have occasionally broken out, such as that referred to by Plutarch, in which the women of Miletus hanged themselves in crowds; whilst in a late epidemic of the same kind at Lyons, the women drowned themselves in the Rhone; and Montaigne, in referring to a similar epidemic which affected the males of Milan, states that as many as twenty-five masters of houses had committed suicide in one week. $\S$ It will be sufficient for the present purpose to state, that the number of suicides in the department of the Seine (France) in the year 1817, were, according to M. Castel, /l 351, of whom 235 were men, and 116 were women; and of this number 186 were married, and 165 were single. In England and Wales the number of inquests on suicides during the year 1861 , का were 1324 , of whom 961 were on men, and 363 were on women. Whilst of 95 individuals who committed suicide at or near Boston (America), ${ }^{* *} 19$ only were women; and Falret, $\uparrow \uparrow$ who may be cited as one of the greatest authorities on this subject, informs us that his own observations have

* De l'Hypochondrie et du Suicide, p. 61. Paris, 1822.

+ Du Suicide, de l'aliénation mentale, et des crimes contre les personnes, comparés dans leurs rapports réciproques, p. 5. 1840.

¥ It is necessary to guard against the error of supposing that such occurrences are altogether unaccountable, for they are partly the result of imitation. This is shown by the frequency with which certain places, such as Waterloo Bridge, are selected by females to commit suicide, and also by the events which led to the top of the Monument, near London Bridge, being enclosed. And lest the popular adage that one fool makes many should be thought to refer in such cases by preference to one sex rather than the other, I may state that when, at certain epochs, the bad example has been set by a member of the male sex, it is sometimes quite as liable to be not only followed by, but also to be limited to, individuals of the same sex, as in the well-known case recorded by Falret (p. 248, note), which nccurred in the year 1772, at the Hôtel des Invalides, in Paris, when in a very short space of time fifteen invalids (male), hanged themselves to a hook which happened to be in a very obscure passage of the Hôtel; the hook was removed, and no more suicides in that place occurred.

§ Falret, op. cit., pp. 170-1.

II Journal complémentaire des Sciences Médicales : quoted by Falret, op. cit., p. 95.

II Lancet, Aug. 2nd, 1862, p. 131.

** Falret, op. cit., p. 18.

t+ Ibid. 
led him to state that suicide is nearly three times more frequent in men than in women.

As illustrations of hereditary suicide limited to males, may be cited a case observed by Dr. Burrows, * in which the suicidal propensity declared itself through three generations; the grandfather hanged himself, and left four sons, one of whom hanged himself, another cut his throat, and a third drowned himself in a most extraordinary manner, after being some months insane; the fourth son died a natural death, which from his eccentricity and unequal mind was scarcely to be expected. Two of these sons had large families; one child of the third son died insane, two others drowned themselves, another is now insane, and has made the most determined attempts on his life. Dr. Burrows further observes, that "several of the progeny of this family, being the fourth generation, who are now arrived at puberty, bear strong marks of the same fatal propensity." A similar case was observed by Moreau, $\dagger$ of a man afflicted with a desire to commit suicide, whose father and paternal uncle had killed themselves, and a brother showed the same overmastering desire : in this case the suicidal monomania of the father and the paternal uncle was probably inherited from a previous generation. In a case recorded by Falleray, + in which a father, son, and uncle committed suicide, and another male relation felt an almost uncontrollable desire to do the same, the heritage may in like manner be referred further back. In a case recorded in the 'Annales Medico-Psychologiques' for 1850 (p. 103), the father committed suicide some years previously; his eldest son voluntarily asphyxiated himself, and another son tried to kill himself in January, 1848 ; his project failed, owing to the vigilance with which he was watched, but on the 11th of September following, he succeeded in doing so by swallowing a large dose of arsenic. In a case of attempted suicide by hanging, of a journeyman whitesmith, aged twenty-two years, related by M. Bourdin, $\S$ the father had previously committed suicide. M. Falret/| relates the following history of a family of suicides. A dyer, issue of healthy parents, but of a very silent disposition, married to a woman of good health, had by his marriage five sons and one daughter; the eldest son, who married and had children, made many attempts at suicide, and finally, when about forty years of age, threw himself one day from the third story of a house and was killed; the second son, also married, strangled himself at the age of thirty-five years ; the third son, in trying, as he expressed it, to fly, threw himself from a window into the garden; the fourth son attempted to shoot himself, but was hindered; the fifth son, melancholic, had not as yet attempted suicide; the sister, who is married and has children, offers no sign which can lead to the suspicion that she shares the

* Op. cit., p. 442.

+ De l'Influence du physique relativement au désordre des facultés intellectuelles, p. 14.1830 .

$\ddagger$ Lancet, 1832-3, vol. i. p. 556 .

$\S$ Annales Medico-Psychologiques, tom. viii. 1846, pp. 312-13, note. \| Op. cit., pp. 296-8. 
melancholy of her brothers; whilst a first cousin, of the male sex and married, has committed suicide by drowning himself in a river. In this case the inheritance, which was strictly limited to the male sex, was probably derived by atavic descent from the grandfather, or some preceding ancestor of the same sex. In another case recorded by Falret,* "an individual (of the male sex) having committed suicide in a house at Paris, his brother, who came to the funeral, exclaimed, on seeing the corpse- "What fatality ! my father and my uncle killed themselves, my brother imitates them, and I have had twenty times the thought of throwing myself into the Seine during my voyage." "A similar confession (adds M. Falret $\dagger$ ) has been made to me by a young officer who came to see his brother, suffering from melancholic aversion to life." Steinau observation, in which a father and son both died by suicide. Whilst sometimes the desired information respecting the influence of sex in such cases, is incidentally afforded in cases recorded for another purpose-as, for example, the suicide of two brothers, in the curious case related by Falret (Obs. 20), of a woman aged thirty-five years, who suffered for a time from suicidal melancholy produced by a persuasion that she inherited the malady from her father and her paternal uncle, and which was afterwards cured when satisfactory proof was adduced by her mother that she was the offspring of another man.

With respect to hereditary suicide in the female sex, Moreau lates the case of Mdlle. B-, who essayed three times to destroy herself; the first time by throwing herself down a well, and the other two times by hanging herself; her mother, mad like herself, had recourse successively to the same means of suicide. In a case recorded in the 'Annales Medico-Psychologiques' for 1847 (tom. x. p. 447), a married woman committed suicide by hanging: she had two daughters and one son; one daughter poisoned herself in September, 1837, and the other daughter also poisoned herself in September, 1847, being exactly ten years later. Falret|| saw, at the Salpêtrière, a girl who had made three attempts to drown herself, and whose sister had drowned herself three years previously. In another case recorded by Falret, बा a grandmother, mother, and daughter were the subjects of suicidal madness. So also in another case of suicidal dementia recorded by Falret, ${ }^{* *}$ affecting C. R. B-, aged sixty-three years ; her daughter had had many attacks of mania, and her grand-daughter had experienced an attack of mania at the age of fourteen years, and had made many attempts at suicide. And in Observation 19 of the same author, is the history of a case of suicidal madness in a young woman, the offspring of a mother who was mad. Whilst in the Times of September 18th, 1862, there is a notice of an inquest held on the body of Sarah Goble, aged seventy-one years, a widow, of the parish of Catsfield, near Hastings, who cut her throat; a sister of the deceased had previously committed suicide at Hayward's Heath Lunatic Asylum.

$$
\begin{aligned}
& \text { * Op. cit., p. } \begin{array}{l}
\text { 7. Ibid. } \\
\text { \& Union Médicale, Jan. 12th, } 1850 \text {, p. } 22 .
\end{array} \\
& \| \text { Op. cit., p. } 6 . \quad \text { II Ibid. } * \text { Op. cit., p. } 293 .
\end{aligned}
$$


Lastly, the two following illustrations will show how involved the heritage in such cases may become when both parents are descended from families in which the suicidal monomania is hereditary. In a case of this description related by Cazauvieilh," a man who was the son and nephew of kindred dead by suicide, took a wife who was the daughter and niece of kindred dead also by suicide; the husband banged himself, and his wife married, a second time, a man whose mother, aunt, and first cousin all committed suicide. And a somewhat similar case occurred lately at Neuilly-en-Thelle, in France, $t$ in which a woman whose father, paternal uncle, and first husband (Firmin Vacquez) had all committed suicide by hanging themselves, married a widower named Cadet Bouché, whose only daughter committed suicide by throwing herself down a well; the second husband, through, it is said, jealousy, committed suicide in the second year after his marriage, in the very same barn as that in which the first husband had hanged himself. In this last case it is possible that imitation partly led to the form of suicide selected by the second husband, although the suicidal monomania in him was undoubtedly hereditary, for the previous suicide of a child by his former marriage proved this.

The development of hereditary insanity and suicide is liable, as many other forms of disease are, to be limited by age as well as sex, and Esquirol, $\ddagger$ in drawing special attention to this fact, states that "hereditary mania shows itself in the fathers and the children, often at the same periods of life; it is excited by the same causes, it affects the same character." The following cases will serve to illustrate the extent to which this conjoined influence may prevail. Dr. Rud. Leubuscher $\S$ records a case observed by himself at Halle, of a peasant who became mad in his twentieth year, in consequence of his taking too much to heart an expression made use of by a preacher, that "all men are sinners;" the father had been seized with mania at the same age. Herman Grube $\|$ relates a case showing the atavic inheritance of insanity at the same age of twenty years, "of a father attacked with mental derangement, who had clever and even distinguished sons, who filled with talent public employments; their children (sex not stated) appeared at first to have sound judgment, but at the age of .twenty years they gave signs of madness." Esquirol 9 relates the case of "a Swiss merchant's two sons, who died mad at the age of twentyfive years." Falret** quotes a case from Voltaire's 'Questions Philosophiques,' of a man of mature age who committed suicide; his father and his brother had both killed themselves at the same age as himself. Prosper-Lucas records the case of a monomaniac who committed suicide at the age of thirty years; his son, having scarcely attained

* Op. cit., p. 321.

† Annales Medico-Psychologiques, pp. 177-8. 1855.

$¥ 0$ p. cit., tom. i. p. 65 .

$\S$ Remarks on the Hereditary Transmission of Insanity: Journal of Psychological Medicine, vol. i. pp. 274-5. 1848.

\| De Morborum transplantatione, sect. 6, c. 1 : Dissert. de Zeller, p. 10.

T Op. cit., tom. i. p. 66.

** Op. cit., tom. ii. p. 728 . 
his thirtieth year, hecame like his father a monomaniac, and made two attempts at suicide. Marc* quotes from Muller the case of a man in the flower of his age, who became melancholic, cousequent on the suppression of a hæmorrhoïdal flux, and drowned himself; his son terminated his existence at the same age by the same mode of suicide. A case is related also by Marct of a man aged forty years, who attempted drowning and was rescued, but who subsequently succeeded in committing suicide; "his father and one of his brothers had terminated their existence at the same age and in the same manner as himself." Prosper-Lucas + relates the following well-known case observed by Michaelis: "Every one of the male posterity of a noble family at Hamburgh, dating back to the great-grandfather, and remarkable for their military talents, was at the age of forty years attacked with madness; there remained only a single descendant, an officer like his fathers, who was forbidden by the senate of the town to marry; the critical age arrived, and he lost his reason." Dr. Rush $\S$ relates the case of twin brothers who did not on the occasion dwell in the same place, and who yet committed suicide about the same time. In the case of a family observed by Esquirol, $\|$ the father, the son, and the grandson committed suicide about the fiftieth year of their life. Lastly, with respect to the female sex, I Esquirol relates the case of a lady who became insane at the age of twenty five years, after her accouchement, and whose daughter became mad at the same age from the same cause; and there are many similar illustrations of puerperal insanity being in like manner hereditarily limited by age.

Closely allied with the foreguing cases of hereditary insanity are those resulting from hereditary intemperance in drink, which, especially in Scotland and other countries far north, where the average consumption of spirits is very great, produces a common form of mental disease known by the name of dipsomania, and which is often limited to the members of one sex in a family. Dr. Inman** states that "drunkenness is often hereditary in a family for centuries, and this quite jrrespective of education and example; I have repeatedly (he remarks) known it to occur where the fathers have died when the children were in infancy, and where the training of their minds had been most carefully attended to." Such occurred in the remarkable case of the Russian family recorded by Gall, ++ in which the father and the grandfather had been early the victims of their over-indulgence in fermented drinks; and the grandson, from the age of five years, showed a marked taste for strong drinks. Dr. Fuchs 杖 has related a case of dipsomania affecting a father and his three suns; the only daughter in the family escaped. In a case of confirmed dipsomania affecting a gentleman

* Op. cit., tom. i. p. 287.

$\mp$ Op. cit., tom. i. p. 759 .

\| Op. cit., tom. i. p. 66.
+ Op. cit., pp. 286-7.

$\S$ Gazette Médicale, 1837, p. 559.

Tा Ibid.

** Foundation for a New Theory and Practice of Medicine, 1860, p. 5, note. t+ Quoted by Esquirol, op. cit., tom. ii. p. 73 .

却 Henke, Zeitschrift, 1837, 3 e Heft, p. 57: quoted by Ch. Rœsch, De l'Abus des boissons spiritueuses, Ann. d'Hygiène Pub., tom. xx. p. 53 . 
belonging to a Scotch family, which has come under my own observation, a first cousin of the male sex on the father's side died from intemperance in drink. In another case of dipsomania in a man aged forty-nine years, which is at present under treatment, a twin brother has been confined for more than twelve months in a lunatic asylum for the same disease; they have three brothers and one sister; the sister is sober in her habits, but one of the brothers gives way occasionally to excess in drink. In the case of a journeyman mechanic, aged fiftysix years, lately under my observation, intemperance in drink not resulting in dipsomania, was associated with asthma, and three brothers also suffered in the same way from intemperance in drink and asthma, whilst their two sisters, one aged fifty-seven, and the other seventy-one years, were both sober and also free from chest affection; the father, who died of paralysis at the age of fifty-one years, and the mother, of some abdominal disease, at the age of sixty-one years, were both sober and free from asthma, but the maternal grandfather was an habitnal drunkard. Lastly, as illustrations of an hereditary tendency to suicide developed in connexion with intemperance in drink, may be cited a case which occurred some years ago in France, ${ }^{*}$ of four brothers who abandoned themselves to unbridled drunkenness, which resulted in the eldest brother committing suicide by drowning, the second by hanging, the third by cutting his throat with a razor, whilst the fourth threw himself from the third floor of a house, but survived; and Esquirol $\dagger$ relates the particulars of a case under his treatment at the Salpêtrière, in which a prostitute, under the influence of drink, had three times attempted suicide by throwing herself into the river Seine, and her sister had previonsly drowned herself whilst overcome with wine.

In like manner the propensity to crime is occasionally observed to be hereditarily limited to one sex, as in the case of kleptomania related by Steinau, + of an old man whose propensity to steal was so strong that he was popularly known as "the thief," and whose son and grandson were both incorrigible thieves; the propensity to steal having shown itself in the grandson at the age of three years.

So also in other abnormal conditions of the brain and nervous system generally, the same influence of sex will be found to prevail in a large proportion of those cases in which a more or less decided tendency to hereditariness has been observed. Excluding such cases as are almost necessarily limited to one sex, whether they occur hereditarily or not-as, for example, hysteria-there remain many cases in which the same limitation by sex, and sometimes also by age, prevail. Haller§ records a case of somnambulism developed in three brothers at the same epoch of their lives. Horstius\| observed a case also of three brothers who were somnambulists; in a case observed by Willis, ๆ

* Gazette des Tribunaux, Avril 13, 1845 . + Op. cit., tom. i. p. 66.

$\ddagger$ Op. cit., pp. 48-50. \$ Biblioth. Medico-Practica, tom. ii. p. 216 .

II De Natura differ. et causis eorum qui dormientes ambulant, \&c. Lipsæ, 1593. Haller: op. cit., p. 216.

TI De Anima Brutorum, pars 1, cap. 1, p. 66. 
a father and his children (sex not stated) were all somnambulists; Dr. Pochon* was acquainted with the case of a medical pupil and his father, both somnambulists : and Prosper-Lucast refers to the case of two sisters, somnambulists, who talked and sustained a continued conversation in their sleep. Whilst in a case of catalepsy observed by Desperrières, $\ddagger_{+}^{\dagger}$ two sisters were successively cataleptic, and their mother had for a long time suffered from nervous affections; and G. Eloch $\S$ refers to the direct transmission of catalepsy from father to son, and also relates a case in which it was transmitted from grandfather to grandson by atavic descent.

Epilepsy furnishes, in like manner, many illustrations of the same influence of sex; and although some difference of opinion has prevailed respecting the extent to which this disease may occur hereditarily, there is sufficient evidence to prove that it does so to an extent greater, perhaps, than many writers appear to be willing to admit; for, in a paper communicated to the Royal Society in 1860, Dr. BrownSéquard announced his discovery that epilepsy artificially produced in guinea-pigs is transmitted to their offspring; and as it is well known that artificially acquired diseases or defects are not transmitted so readily as those which occur, as it were, naturally, it may be inferred from this that epilepsy is a disease naturally liable to be transmitted hereditarily; and the following eases have been selected to show the extent to which the influence of sex prevails in the different forms of its hereditary descent, whether direct, atavic, or collateral. Gintrac\| relates the case of the Marquis Ant. Jules Brignole, attacked with epilepsy, who had a family of four sons and two daughters; the second and third sons had epilepsy, but not the other children. Dr. Hamilton था relates a case of epilepsy in father and son. Dr. Russell** (of Birmingham) records the case of a mother and her daughter, both epileptic; and another case in which a gunsmith became epileptic at the age of eighteen years, his father and his maternal uncle having both been epileptic; it is to be noted that the inheritance in this case was double, being direct on the father's side, and collateral on the side of the mother. Moreautt relates the case of a woman named Martin, aged fifty-three years, and the mother of eight children; she had been epileptic since the age of seven years, and her mother also was epileptic; of Mrs. Martin's eight children, three died from convulsions (sex not stated), and of the five remaining, one daughter is hysterical, and another (younger) daughter is epileptic. It is to be further noted in this case, that whilst epilepsy was hereditary in the females of the family for three generations, both the father and the paternal grandfather of Mrs. Martin were insane, affording an illustration of insanity

* Arch. Gén. de Méd., tom. xiv. p. 539.

† Op. cit., tom. ii. p. 790 (from Casimir Medicus, Maladies Périodiques, p. 27).

‡ Histoire de la Soc. Royale de Méd., tom. v. p. 251.

§ Catalepsis Epileptica : quoted by Prosper-Lucas, op. cit., tom. ii. p. 735.

II Op. cit., p. 319 . If Medical Commentaries, vol. vii. p. 336.

** Medical Times and Gazette, Feb. 22nd, 1862, pp. 187-8.

t† La Psychologie Morbide, p. 139. 1859. 
being hereditarily limited to one sex, and epilepsy to the other, in the same family. Maisonneuve* relates an interesting and well-marked case of the atavic occurrence of epilepsy in a man, a native of Versailles, in whom epilepsy commenced immediately after birth; the father and mother had never been subject to epilepsy, but the maternal grandfather was epileptic: and Dr. Sieveking informs me that he has under treatment a case of epilepsy in a little boy aged five years, whose maternal grandfather, aged sixty-nine years, has recently had two or three epileptic seizures; in both of these cases the transmission of the. disease through the mother agreed with the most common form of atavic descent. Sir Henry Holland tobserved a case in which epilepsy affected three sisters; Gintrac $\$$ records a case of epilepsy occurring in two brothers; and I have at present under observation a case of epilepsy occurring in two brothers, which began at the age of fourteen years in each, their two sisters, one aged twenty-one and the other eighteen years, being free from the disease. In the case of a dressmaker, aged twenty-eight years, married and the mother of two children, which has lately been under my observation, epilepsy began at the age of sixteen years, and two of her maternal aunts, being the second and seventeenth children of a family of six sons and twelve daughters, have suffered from the disease, which began in them also at the age of sixteen years; it is to be noted in this case, that the maternal grandmother had a family of two sons and eleven daughters, showing an hereditary tendency on the female side to large families, consisting chiefly of daughters. In the following case, which has likewise come under my own observation, the development of the disease was also limited by age as well as sex: a married couple, in whom no previous history of epilepsy could be traced, had ten children, of whom the second, third, fourth, fifth, sixth, and ninth were boys, in all of whom epilepsy was developed between the ages of twelve and eighteen months; whilst the first (now aged seventeen years), seventh, eighth (dead soon after birth), and tenth were girls free from the disease. In the well-known case of Peter the Great, of Russia, $\S$ in whom hereditary epilepsy showed itself at the age of five years, the females of the family seem to have been exempt from the disease; respecting the father of Peter the Great, Alexis Michaelowitz, little appears to be known of his medical history, beyond the fact of his being carried off by a premature death at the age of forty-six years. This prince was twice married; by his first wife he had two sons and six daughters; the eldest son, Feodor, who mounted the throne at the age of fifteen years, was of a feeble temperament-the second son, Ivan, nearly deprived of sight and speech, was often attacked with epileptic convulsions; whilst of the six daughters, one, the Princess Sophia, was distinguished for her talents, and the others are not specially mentioned. By his second marriage Alexis left two children, Peter the Great and

* Recherches et Observations sur l'Epilepsie, p. 68. † Op. cit., p. 43.

$\ddagger$ Op. cit., quoted from Revue Médicale, 1828, tom. iv. p. 102.

§ Moreau: op. cit., part 3, Faits Biographiques, pp. 520-1. 
the Princess Nathalie. Respecting the family of Peter the Great, which consisted of six sons and two daughters, one son, Alexis, was so headstrong and vicious that he was put to death by his father, and the five other sons died in infancy or soon afterwards; a grandson of Peter the Great, Paul I., suffered from hallucinations, and on one occasion was to be seen rushing through the streets of St. Petersburg, pursued, as he fancied, by the spectre of his grandfather. In this case the epilepsy of the half-brothers, Peter and Ivan, sons by different marriages, was probably derived from a paternal ancestor by atavic descent. Whilst the following case, recorded by G. L. Durius, ${ }^{*}$ may be cited to illustrate Dr. Brown-Séquard's observations respecting the hereditary transmission of acquired epilepsy; a man, who was not born epileptic, shattered the dorsal vertebræ in falling from the top of an oak; the result of this accident was a spasmodic contraction of the limbs, which lasted for years, and was not perfectly cured when he married; his son, on attaining the age of puberty, became epileptic.

The same influence of sex may also be observed in many cases of hereditary headaches, affecting either one or the other sex; and as an illustration of its occurrence in the female sex, may be mentioned the case of a lady, lately under my observation, whose hair became quite grey at a comparatively early age, from frequent paroxysms of intense headache, for which there seemed to be no means of relief; her daughter suffered in the same way, though to a less extent, whilst her two sons were exempt. Piorryt speaks of a hospital practitioner in whose family exist, from fither to son, headaches in connexion with a nervous disturbance of the stomach. Prosper Lucast. relates the case of a gamekeeper afflicted, like his father and paternal grandfather, with the same malady (headache), which continues in each of them up to the age of forty years, when it changes into a sensation of weight on the top of the head, unaccompanied by cephalalgia, nausea, or vomiting. And $\mathrm{Dr}$ Henry Stewart has furnished me with a still more complete illustration of this associated influence of age and sex, in the case of a married man, aged forty years, without children, who suffers from severe paroxysms of headache, which are only relieved by the recumbent posture in a dark room; repeated change of climate has been tried, and many medical practitioners have been consulted without benefit; tonics give most relief, but under all kinds of treatment the headaches come on once and often twice a week, and have recurred in this way ever since the age of twelve years, when they first commenced; his three brothers suffer in the same way, but not his sisters; in his father they began during childhood, and continued till the age of fifty-five years, when they entirely ceased; his paternal uncles, paternal grandfather, and paternal granduncles have all suffered from severe headaches in the same way, which in like manner ceased in those who lived to the age of fifty-four or fifty-five years; none of the females of the family have ever suffered from these headaches.

Lastly, in cases which may be directly referred to some structural

* Ephém. d'Allem., Déc. 3rd, an. 9-10, obs. 126.

+ Op. cit. p. $116 . \quad \neq$ Op. cit. tom. ii. p. 702. 
lesion of the brain, the same influence of sex has not unfrequently been observed. For example, in cases of hydrocephalus, in addition to the well-marked illustration already referred to,* may be cited the following cases recorded by Otto : $†$-a case observed by P. Frank, in which five sisters died in their first year of acute hydrocephalus; one family in which three, and another in which seven sisters had water in the head, observed by Goelis; and a case observed by Rolph, in wlich seven sisters were affected with this disease, of whom only the youngest was cured. It may moreover be remarked that in the same way that a double heritage has in other forms of hereditary disease caused both the male and the female offspring to be similarly affected, so likewise in a case of hydrocephalus related by Prosper Lucas, $\neq$ in which seventeen children in one family were attacked, and only one recovered; the mother was so affected in the head that she could never be taught to read, and the father had been affected since his youth with incurable deafness, and wás moreover very eccentric; whilst his first cousin, on the day of his marriage, dropped dead at table from a stroke of apoplexy; and Piorry relates a case of encephalitis which was fatal to a father, mother, and sister in one family. The influence of age combined with sex is well shown in the case observed by Sir Henry Holland, \| of hemiplegia occurring in three brothers at the same age; and, in connexion with this division of our subject, may be cited the case recorded by J. F. Meckel, बा of hernia cerebri occurring in two sisters as a congenital defect.

(To be concluded.)

\section{ART. II.}

Researches on the Treatment of Suspended Animation. By Benjamin W. Richardson, M.A., M.D., Senior Physician to the Royal Infirmary for Diseases of the Chest.

In commencing this history of my researches on re-animation, I must beg that the opinions and views expressed may be received apart from the experimental details. The experimental portions are mere matters of fact, and as such they remain; on them other minds may freely and fairly draw conclusions different from my own. Offering candidly this preliminary statement, I must ask, on my part, that the views I have expressed may be received with equal consideration. That these views may differ from received doctrine, is quite in accordance with my expectations; but as I put them forward sub judice and with moderation, 1 cannot but hope that their faults and shortcomings may, by exciting attention to the all-important topic on which they treat, be of service to science and humanity.

That no misunderstanding may hereafter occur, it is necessary at the outset to define rigidly the class of cases to which the term sus-

* British and Foreign Medico-Chirurgical Review, July, 1861, p. 209.

† Op. cit., p. 379 . II Op. cit., p. 43. $\ddagger$ Op. cit., tom. ii, p. 741 .

$\S$ Op. cit.

बI D. Archiv f. d. Physiol., vol. vii. p. 99 , ff. 